\title{
ADDITIVE REFURBISHMENT OF A VIBRATION-LOADED STRUCTURAL COMPONENT
}

\author{
Ganter, Nicola Viktoria; \\ Ehlers, Tobias; \\ Gembarski, Paul Christoph; \\ Lachmayer, Roland \\ Leibniz University Hannover
}

\begin{abstract}
In the event of damage to additively manufactured components whose shape cannot be produced by machining, an additive repair can potentially be not only ecologically but also ecologically more favorable than the production of a new component. In addition, a number of hurdles that otherwise often impede the use of additive repair, e.g. the availability of the material of the damaged component for the additive process, are eliminated. As far as the authors are aware, this publication is the first to present a process for the additive refurbishment of additively manufactured components using the example of a wheel carrier. In this context, the possibility of increasing the fatigue strength of a structural component in refurbishment is discussed for the first time. To increase the fatigue strength of the wheel carrier, the chosen approach is to integrate the effect of particle damping into the component. Particularly in the case of components subjected to bending stresses, the effect of particle damping can be integrated into the component's interior without having to accept a significant loss of strength.
\end{abstract}

Keywords: Additive Manufacturing, Additive Repair and Refurbishment, Particle Damping, Case study, Circular economy

\author{
Contact: \\ Ganter, Nicola Viktoria \\ Leibniz University Hannover \\ Institute of Product Development \\ Germany \\ ganter@ipeg.uni-hannover.de
}




\section{INTRODUCTION}

In recent years, additive manufacturing (AM) has left its niche existence in rapid prototyping and moved towards the manufacture of end products, so-called direct manufacturing (Wohlers, 2018). Since direct manufacturing offers high added value as well as an increase in market share and turnover, the question arises how additive manufactured components are treated at the end of life from both economic and ecological aspects. For example, conventionally manufactured products are often not repaired, as the production of new parts is often cheaper than repair. However, for additive manufactured products, the same process can be used for repair as for production. Thus, the repair can be carried out with a lower resource input in terms of material and energy, economically and ecologically, and the sustainability aspect can be addressed.

Additive repair has already been successfully used to repair components. However, as far as the authors know, additive repair has so far only been used for conventionally manufactured components. Several obstacles, however, are avoided during the repair of additively manufactured components, which would otherwise complicate the use of additive repair. For example, the CAD data of additivemanufactured products is available for the repair process and therefore no reverse-engineering is required for its identification. Furthermore, the characteristics of the component always allow it to be processed using an additive process chain. For example, the alloy of the broken component is processable and available for repair. Accordingly, it is possible to use exactly the same alloy with the same process parameters for repair as in the manufacturing process, thus no verification of material compatibility is necessary. In this context, another important point is that the company already has know-how in the field of AM. In addition, assuming that the same material is used, potentially less effort is required to qualify the repair process, since the repair does not differ significantly from the actual manufacturing process. Overall, this can reduce rejects. Moreover, in the case of minor damage, the repair is faster than the new parts AM process, which means that lead times can be increased and the time required to provide spare parts can potentially be reduced.

Especially to adapt a component to new or changed requirements or to increase the resistance of the component regarding the cause of damage, the use of additive processes offers a great potential, e.g. by a high achievable degree of function integration. In the following, this will be understood under the term additive refurbishment. So far, the integration of additional functions in the context of additive refurbishment has rarely been realized in use cases in the literature. Centerline shows, for example, in a case study the extension of an engine block by a mounting for an additional sensor (Centerline, 2012).

In the case of refurbishment with regard to a cause of damage, previous examples of application are limited to an increase in resistance with regard to corrosion and/or tribological stresses, usually through coatings (Birger et al., 2011). So far, there is a lack of examples for the refurbishment of structural components that failed due to cracks or fractures caused by mechanical stresses. However, the literature offers a variety of solution principles to optimise a component with regard to mechanical stresses. For example, vibrations of dynamically loaded structural components can be effectively reduced over a wide frequency range through the effect of particle damping (Ehlers and Lachmayer, 2020; Lu et al., 2017). Furthermore, this effect can be directly integrated into the interior of the component by means of the additive process Laser Powder Bed Fusion (LPBF) (Scott-Emuakpor et al., 2018; Ehlers et al., 2021).

This paper presents a procedure for refurbishing the wheel carrier shown in Figure 1. The wheel carrier is a vibration-loaded structural component manufactured additively in LPBF, which failed due to cracks in the arms near the tie rod connection (dotted box). This damage occurred in the early use phase, so it is assumed that the service life can only be increased by a load-adapted refurbishment. The aim of the refurbishment is therefore to increase the fatigue strength and thus the service life under the acting loads. To achieve this, the approach chosen is to reduce the vibrations by integrating the effect of particle damping into the wheel carrier. 


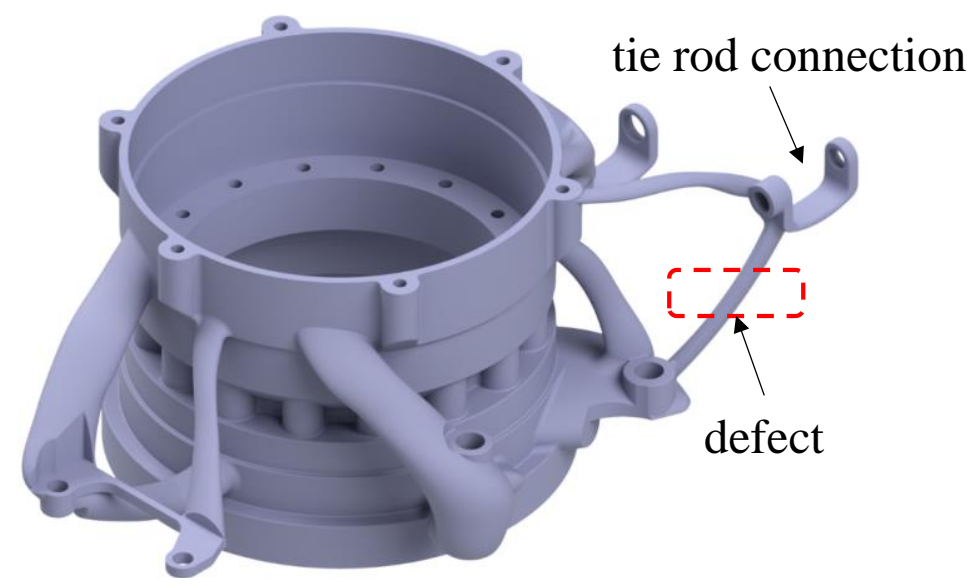

Figure 1: Wheel carrier with cracks in the area of the dotted box

\section{THEORETICAL BACKGROUND}

\subsection{Additive Repair}

For the repair of metallic components, the additive manufacturing processes Direct Energy Deposition, Laser Powder Bed Fusion and Cold Spray are identified from the literature as suitable (Leino et al., 2016; Wasono et al., 2019; Yeo et al., 2017; Zghair and Leuteritz, 2017). The methods allow direct material application to the damaged component. Their fields of application differ significantly, due to different process-specific restrictions. For the repair in LPBF, for example, a decisive restriction is that the size of the components must allow material to be applied in the closed building space of the system. For current systems, this is $250 \mathrm{~mm}$ x $250 \mathrm{~mm}$ x $325 \mathrm{~mm}$ (Lachmayer and Lippert, 2020; Gasser et al., 2010). Gasser et al. (2010) use LPBF to produce the component areas to be repaired separately as patches. Subsequently, these are joined to the component by a welding process. This method can also be used to repair components whose dimensions exceed the building space of the LPBF system. Another restriction of LPBF for repair is that material can only be applied to flat surfaces which are in one plane with the surface of the powder bed during material application. Therefore, prior to LPBF, material may need to be removed from the part to provide a flat surface. Thus, depending on the component geometry and the location of the damage, a large portion of the undamaged component volume may have to be removed. These examples are intended to illustrate that in order to assess the additive reparability of a damaged component, its characteristics must be compared with the restrictions of the individual additive processes, e.g. the building space or the feasible minimum structure size.

Like additive manufacturing, the process chain of additive repair is basically divided into the process steps pre-process, in-process and post-process. The main differences between repair and additive manufacturing of a component are described in more detail below.

At the beginning, the data for the automated additive material application must be generated. To do this, the shape of the damaged component must be recorded and compared with the undamaged geometry. Complicated component geometries are digitised using optical methods and then compared with the $\mathrm{CAD}$ data of the undamaged component. If no corresponding 3D model is available, a reverse engineering process is required for reconstruction (Wilson et al., 2014). Furthermore, a suitable material must be selected for the repair. A prerequisite for additive repair is that the material of the component to be repaired or a compatible material is available as a starting material for the additive repair process (Zghair and Leuteritz, 2017).

Before the additive material is applied, the damaged component is usually prepared. In this process, damaged component areas are removed and access for the additive material application is created. The amount of material to be removed depends on the existing damage (type, shape, position and size), the choice of repair method and the accessibility of the repair zone for the following process steps (Jhavar et al., 2013). In addition, additive repair usually requires the construction of a fixture to hold the component in place during additive material deposition. Before the additive material application in the in-process, the component is positioned and fixed in the building space of the additive manufacturing system. If the additive manufacturing system does not have automatic component recognition, e.g. by 
means of a camera system, the position and orientation can be measured manually and the starting point or plane for the additive material application can be determined.

In the automated building process, the desired structures are built up layer by layer. Subsequently, in the post-process, the component is removed from the system, cleaned, quality assurance measures are carried out and, if necessary, further post-processing steps are performed, e.g. the mechanical preparation of functional surfaces. The quality assurance measures chosen depend on the repair process carried out and the required properties of the component. Andersson et al. (2017) applied a nickel-based alloy on the base material steel in the LPBF repair process of gas turbine burners. Due to the different materials, they evaluated the microstructure of the interface through polished crosssections of repaired components and the relevant material properties using test specimens. In addition, a series of functional tests were also carried out both in laboratory test benches and in the machine. After successful functional and operational tests, the repaired components were installed in the gas turbine and long-term field validation was carried out.

\subsection{Particle Damping}

Laser powder bed fusion is an additive manufacturing process in which the component is built up layer by layer by locally melting powder (Lachmayer and Lippert, 2020; Ehlers et al., 2020). In addition, LPBF enables the targeted integration of unmelted powder inside the component and thus the integration of the effect of particle damping (Künneke and Zimmer, 2017; Vogel et al., 2019; Ehlers and Lachmayer, 2021). Through the combined forces of inelastic impacts and friction, either particle/particle or particle/wall interaction, kinetic energy is absorbed from the vibrating main structure resulting in increased damping (Friend and Kinra, 2000; Lu et al., 2017). On the left side of Figure 2 is a schematic representation of the particle damping and on the right side the qualitative effect of the particle damping related to the initial situation. The frequency transfer function (FRF) shows a clear drop in amplitude for the particle damping. This passive vibration reduction measure is also effective over a wide frequency range from a few $\mathrm{Hz}$ to high-frequency applications up to several $\mathrm{kHz}$ (Papalou and Masri, 1996; Panossian, 1992; Friend and Kinra, 2000; Fowler et al., 2000; Lu et al., 2017; Ehlers et al., 2021). Another advantage of a particle damper is that it has little effect on stiffness and mass of a component when properly designed (Scott-Emuakpor et al., 2018; Lu et al., 2017; Xiao et al., 2016).
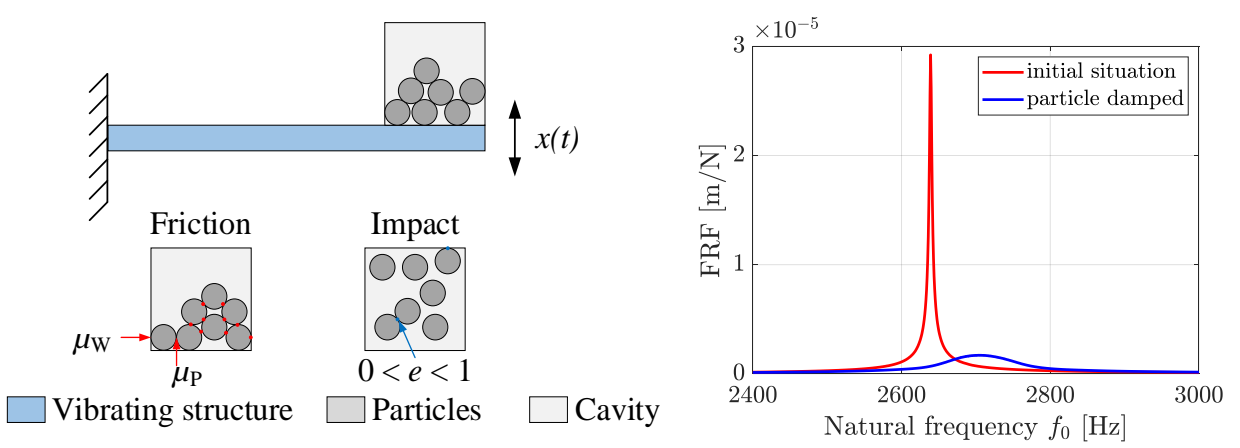

Figure 2: Schematic diagram of a particle damper (Ehlers et al., 2021; Ehlers and Lachmayer, 2021)

\section{METHOD}

In order to increase the service life of the wheel carrier, its shape is to be modified in a refurbishment process. In the following a procedure is presented, the general steps of which are shown in Figure 3.

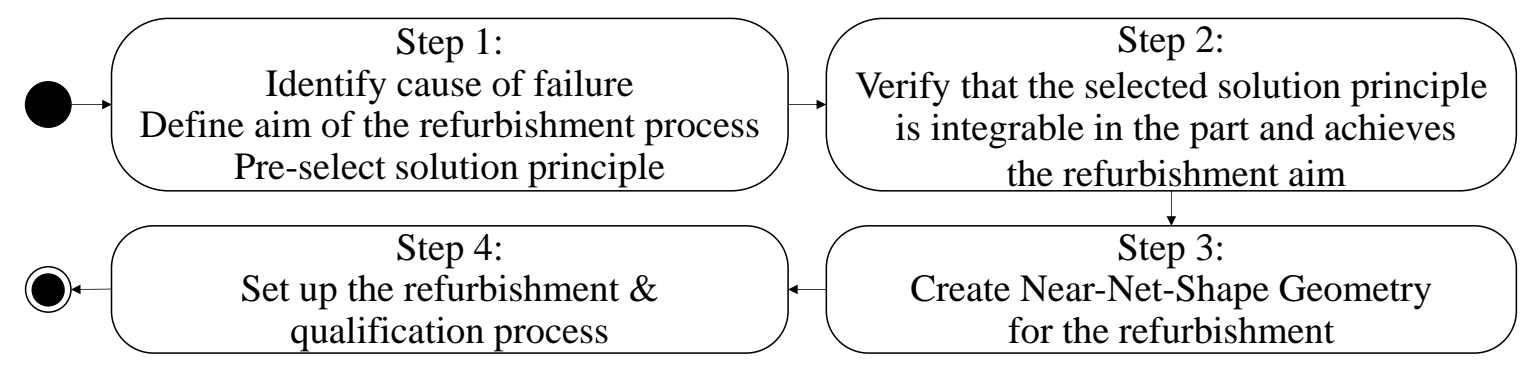

Figure 3: General procedure for refurbishing the wheel carrier 
The first step is to define the goal of the refurbishment process. As the wheel carrier failed in the early use phase due to cracks, a refurbishment is to be carried out with the aim of increasing its service life. For this purpose, the vibrations of the dynamically loaded structural component are to be reduced. As possible solution principles for vibration reduction, dynamic vibration absorption, vibration isolation and vibration damping were identified. In addition, the structure can also be thickened to withstand increased vibration loads. Since the aim is to achieve a high level of rigidity for the wheel carrier with a low mass at the same time, particle damping is preselected as the most suitable solution principle as a subcategory of vibration damping. As shown in the literature section, the effect of particle damping is one way of effectively reducing vibrations. By means of Laser Powder Bed Fusion it is possible to leave unmelted powder inside the component in a targeted manner, thus making use of the particle damping effect. Especially for components or component areas that are subjected to bending loads, powder-filled cavities can be integrated near the neutral fibre, thus achieving high damping without a significant loss of strength (Ehlers and Lachmayer, 2021; Ehlers et al., 2021). Since the arm of the wheel carrier near the tie rod connection failed under bending load, the effect of particle damping is further pursued for refurbishing the wheel carrier.

In the second step, it is evaluated whether the effect of particle damping can be integrated into the component structure and whether the integration of particle damping is suitable to significantly reduce the vibrations occurring during operation of the wheel carrier. Since the effect of particle damping is highly non-linear, it has to be evaluated for the component design. In particular, the question must be answered as to how large the cavities must be designed in order to achieve the desired damping or vibration amplitude. The size of the cavity represents a decisive design parameter for setting the damping. High damping can usually be achieved by a large cavity, but stiffness and strength aspects must also be taken into account. This means that the wall may not be as thin as desired and manufacturing restrictions must also be taken into account. For this purpose, the procedure shown in Figure 6 is presented below, with which the achievable damping can be estimated.

After particle damping has been selected as a suitable measure for vibration reduction, a dynamic simulation or modal analysis of the wheel carrier must be carried out. This identifies the areas with the highest amplitudes. In these areas the powder-filled cavity can be integrated later. Especially for the modal analysis the assembly around the wheel carrier should be integrated into the simulation. In this way, its influence on the vibration modes of the wheel carrier is taken into account. The third mode at $249 \mathrm{~Hz}$ results in a critical vibration of the defective arm (see Figure 4). It can be seen that the powderfilled cavity should be integrated into the holder to the tie rod, because there the deflections are highest.

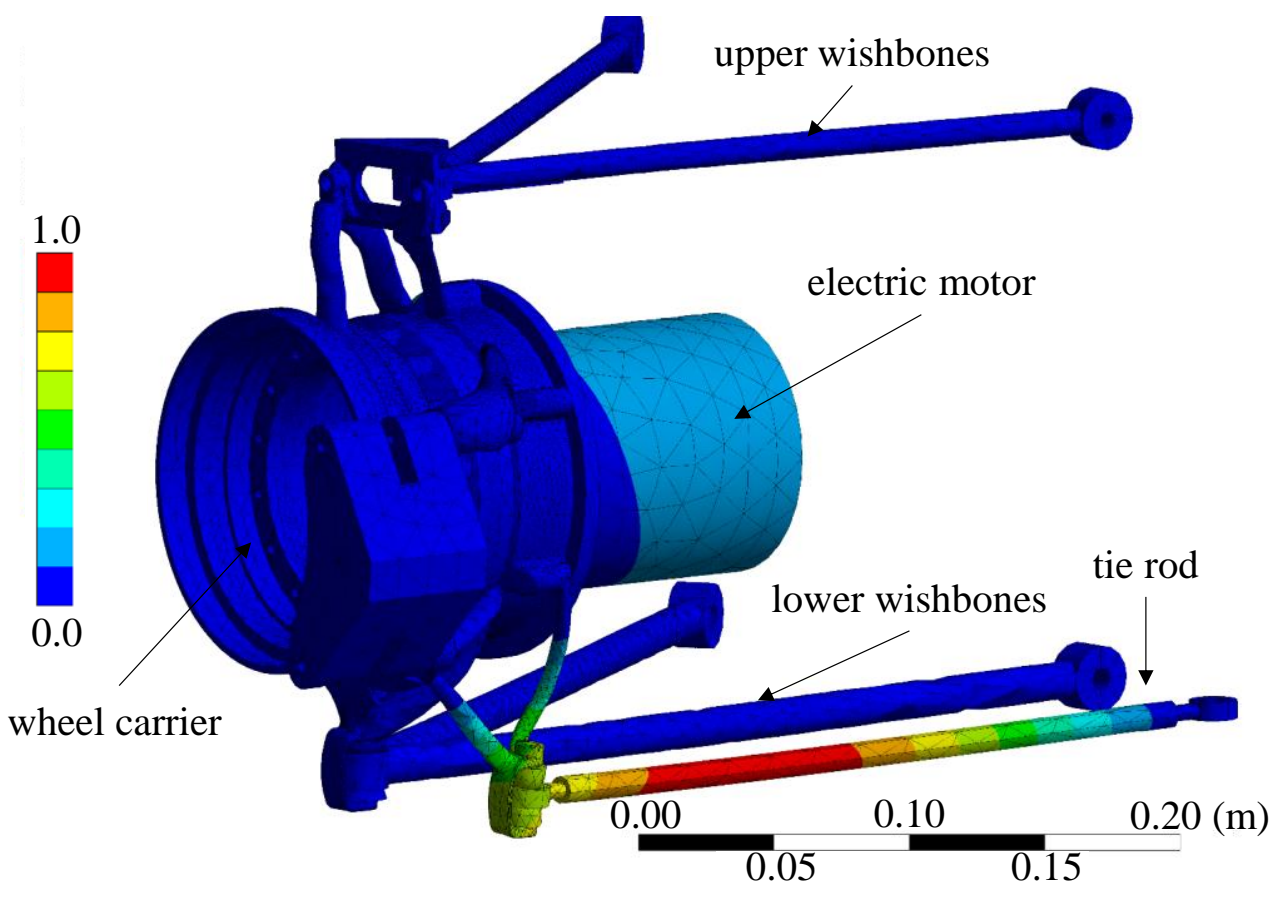

Figure 4: Modal analysis of the wheel carrier assembly 
Since the effect of particle damping is frequency and force dependent, the natural frequencies and excitation frequencies as well as the corresponding loads must be identified. The loads are assumed to be disturbing vibrations due to the unevenness of the road surface, which can be up to 10 times the acceleration due to gravity, depending on the ground. Depending on the load case (tension, compression, bending, torsion), the damping values must sometimes be re-determined. As there are usually no damping values available for these boundary conditions, they must be identified either simulatively or experimentally, for example by a parameter study.

For the present work a Design of Experiment (DoE) is carried out to characterise the damping properties. The detailed results of the DoE are presented in (Ehlers et al., 2021) and are briefly described below. The aim is to determine the relevant design parameters natural frequency, excitation force and cavity volume. As the arm of the wheel carrier had failed under bending load, the DOE is carried out in the form of a parameter study using laser beam melted bending beams. A total of 26 parameter combinations are investigated. In addition, AlSil0Mg was chosen as the material, as the original model of the wheel carrier was made of AlSi10Mg.

In the parameter study, the beams are supported on foam and excited to oscillate by means of an automated impulse hammer (see Figure 5). The vibrations are detected by an acceleration sensor on the back of the beam. The damping can be calculated from the frequency transfer function (FRF) using the Circle-Fit method. Three exemplary FRF are shown in Figure 5 for the $5 \times 5 \times 200 \mathrm{~mm}^{3}$ beams. The amplitude curves show a broadband decrease of the vibration amplitudes from $600-18000 \mathrm{~Hz}$. From this result it can be concluded that the effect of particle damping is effective if the cross-section of the cavity is larger than $\mathrm{A}=3 \mathrm{~mm}^{2}$ and is therefore suitable for integration into filigree structures. The further results of the parameter study show that the damping can be increased by a factor of more than 20 with an optimum design. Overall, the parameter study characterises a force and frequencydependent course of the damping. The force is varied from 10 to $200 \mathrm{~N}$ and thus covers the range of the disturbing vibrations occurring at the wheel carrier. The results can be stored in a knowledge database in order to make them accessible for future refurbishment processes. Thus, it is possible to transfer the damping values to the arm of the wheel carrier. This procedure is shown in the form of a flow chart in Figure 6.
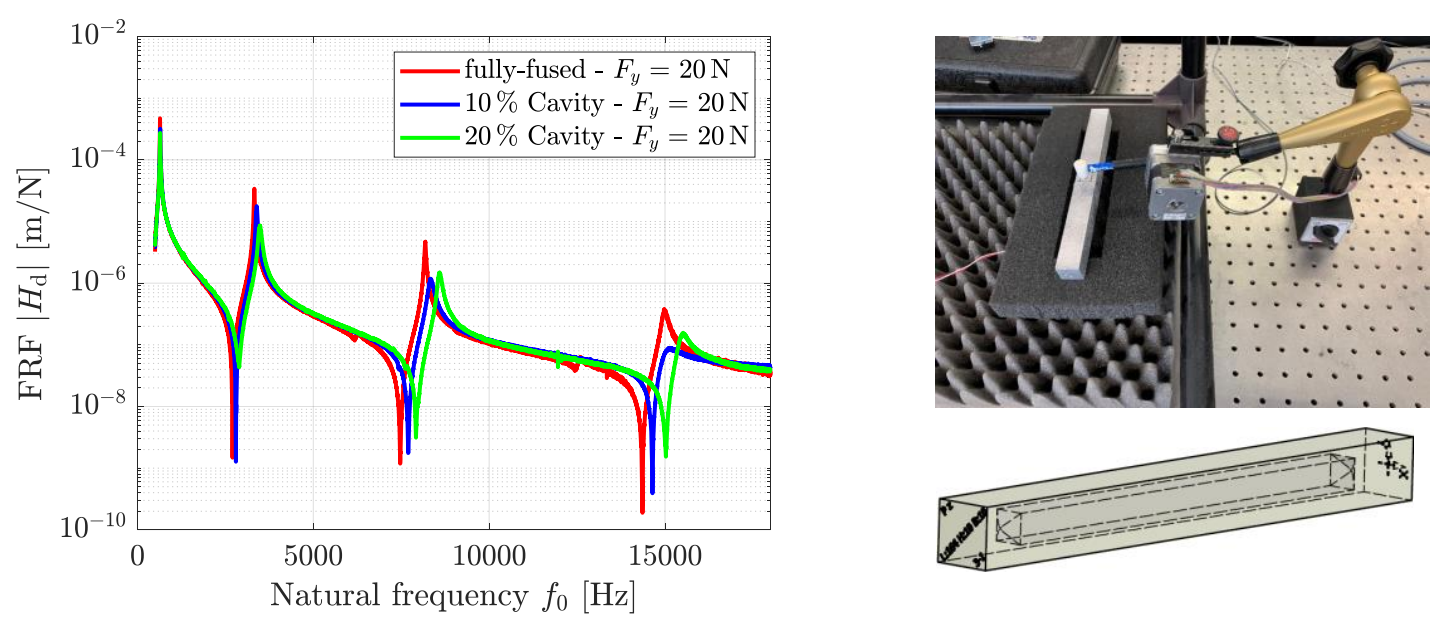

Figure 5: Frequency response function of three $5 \times 5 \times 200 \mathrm{~mm}^{3}$ beams (left), automated impulse hammer excitation of the beams (right above), CAD model of the particle-filled beams (right below) (Ehlers et al., 2021; Ehlers and Lachmayer, 2021) 


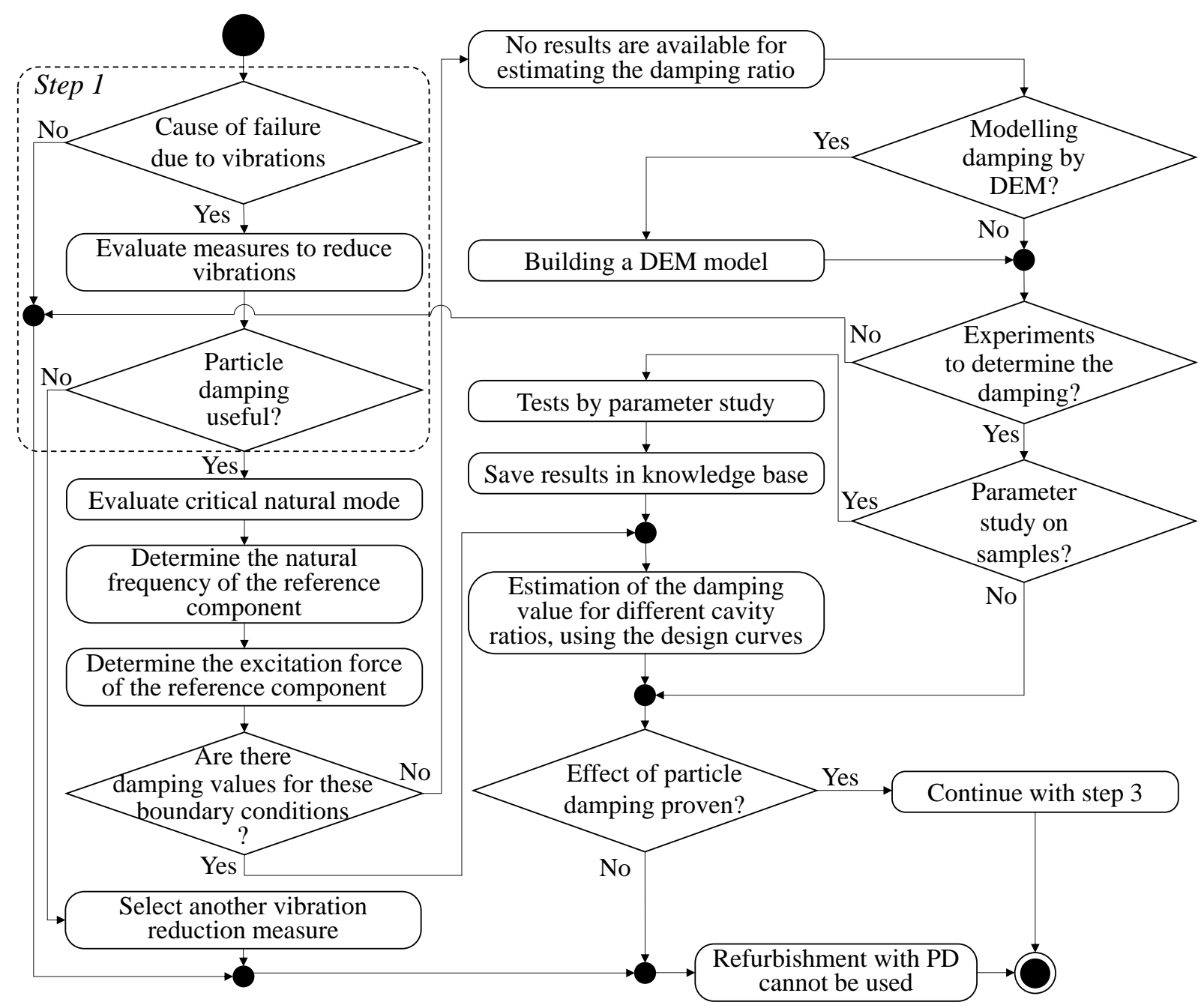

Figure 6: Flow chart for the integration of particle damping in a refurbishment process, based on (Ehlers et al., 2021; Ehlers and Lachmayer, 2021)

The third step is the adaptation of the component for the repair. This includes the integration of the particle-filled cavities, in the areas of the highest amplitudes near the tie rod connection. After the integration of the cavities into the model, it is checked whether the design meets the manufacturing restrictions of the LPBF. For example, the downskin surfaces of the cavities must maintain a downskin angle of $45^{\circ}$ in order to be manufactured without support structures. It must also be checked whether the minimum required wall thickness is maintained after the cavities have been inserted. Otherwise, the corresponding component areas will be thickened. To generate the near-net-shape geometry for additive material application, the cutting plane must then be defined. Up to the cutting plane, material is removed in the part preparation and the new structure is built up on this by LPBF. The cutting plane must be selected in such a way that the component areas changed by particle damping can be integrated into the component. According to (Zghair, 2019), the cutting plane should also be positioned outside the maximum stresses. Furthermore, the cutting plane of the wheel carrier should be aligned in such a way that the arms can be manufactured upright in the build space of the LPBF system without support structures (see Figure 7).

Subsequently, a static strength verification and a dynamic simulation are carried out to verify the properties. In particular the fracture zone and the cutting plane are analysed. Furthermore, a process simulation of the additive repair process can be performed. Following this, the digital model for the additive material application can be created. 

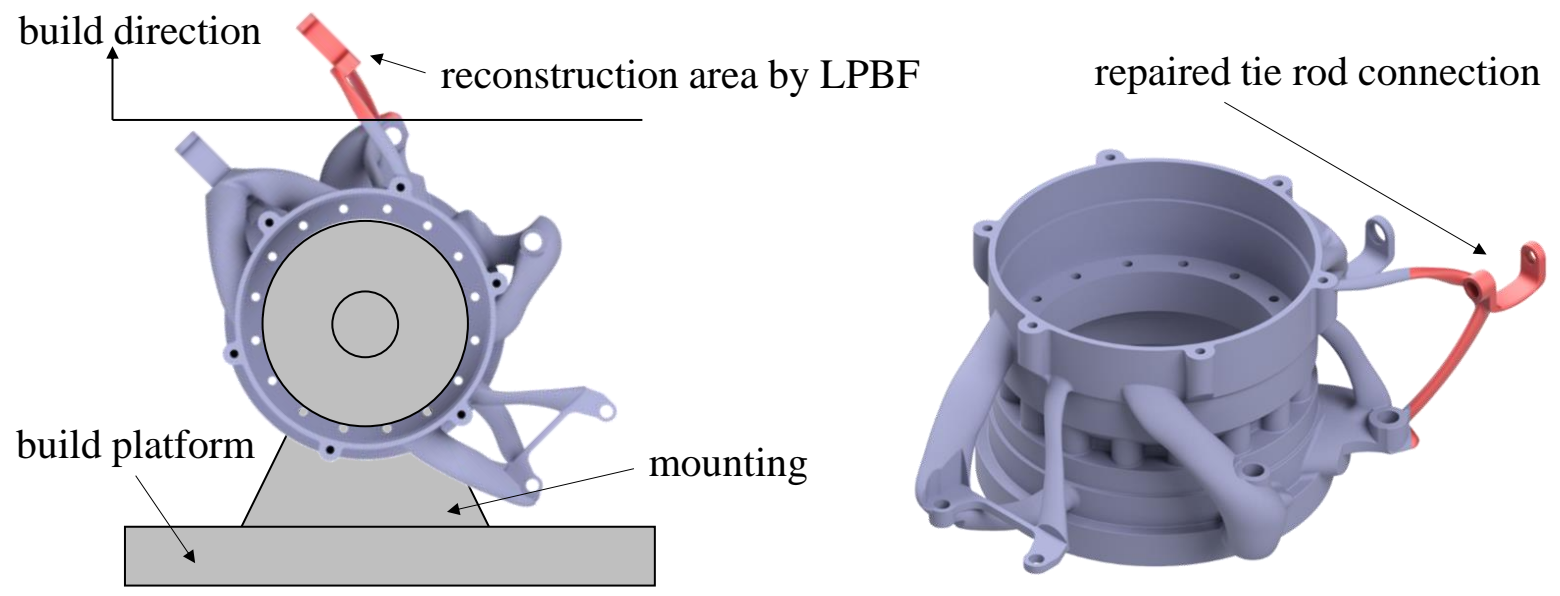

Figure 7: Positioning of the wheel carrier for additive repair (left), repaired wheel carrier (right)

The fourth step is the physical repair process. The LPBF was chosen as the additive repair process, as this process is suitable to integrate the particle damping into the component to be repaired. Furthermore, the component and damage characteristics, such as the dimensions, the material and the accessibility of the damage, allow processing in the LPBF.

Before the material is applied, a holder is designed and manufactured to fix the wheel carrier in the LPBF system according to the cutting plane. Furthermore, the wheel carrier is prepared for the additive material application. In a CNC milling machine, the cutting plane on the component is produced by removing material by cutting. The component is then aligned and fixed in the building space of the system. As with additive manufacturing, the digital preparation includes the slicing of the near-net-shape model and the definition of the machine parameters, e.g. the laser power and scanning speed. Since in the repair process of the wheel carrier both the base material and the applied material are AlSi10Mg (additive processed), the standard machine parameters are selected for this material. A parameter study is not necessary.

After the additive material application, the component is removed from the building space of the machine, cleaned and the functional surfaces are machined. The result of the repair process is then evaluated. Computer tomography (CT) is used to check whether the cavities have been manufactured without defects and how much powder they actually contain. Furthermore, CT images are used to check whether porosity, cracks or blowholes are present in the interface resp. cutting plane. The fatigue strength of the wheel carrier is then examined on a test rig. The driving profile from driving simulations and measurement data is simulated on the test bench in the temperature range from $+40^{\circ}$ to $-40^{\circ}$.

\section{Discussion}

This paper describes a method for repairing a vibration-damaged component, which is improved by particle damping. Further work is required to apply and evaluate the presented method on the wheel carrier. This includes the final design of the wheel carrier as well as the verification of properties by static and dynamic simulations and test bench trials. Only on this basis will it be possible to generalise this method.

The refurbishment is to be used for the additive-manufactured wheel carrier because it failed in the early phase of use due to dynamic stress. In addition, it is assumed that the repair is more costeffective than the production of a new part due to material savings and reduced production time. It is presumed that the cause of the early damage is an incorrect design, such that the damage would occur again with a simple repair. Accordingly, a refurbishment is necessary to extend the service life. An advantage of additive refurbishment of additively manufactured components is that information is available on the load conditions, which can be used to optimise the component during repair. A requirement, however, is that only a certain part of the component may be damaged and the rest of the component must be intact.

Another criterion for refurbishment is poor component performance, such as loss of comfort due to hand-arm vibrations in a motorcycle triple clamp. Further work should examine the economic efficiency of additive repair \& refurbishment for additively manufactured components. Especially for larger batch sizes, additive refurbishment could be economically viable, since the engineering effort 
can be allocated to several components. This work can contribute to the inclusion of additive repair \& refurbishment in the spare parts strategy of companies.

For the refurbishment of the wheel carrier, a direct material application by means of LPBF was provided in this paper. An alternative repair method is to manufacture the arms using LPBF and weld them to the wheel carrier afterwards. Provided that this procedure is technically feasible for the wheel carrier, it could be more economically and ecologically sensible, as less material has to be removed and reapplied. This repair method could also be particularly relevant for the repair of components which, due to their dimensions, do not allow processing within the LPBF machine.

\section{CONCLUSION}

Additive manufactured components usually cannot simply be replicated or repaired by means of chipping production, so that additive manufacturing processes must be used here in a targeted manner. This eliminates a number of problems that are otherwise seen as obstacles to the use of additive repair $\&$ refurbishment. As far as the authors are aware, this article is the first to present a procedure for the additive refurbishment of additive manufactured components, using the example of a wheel carrier. Likewise, the improvement of the fatigue strength of a structural component through a refurbishment has not been described in the literature so far. To increase the fatigue strength of the wheel carrier, the approach chosen was to integrate the effect of particle damping into the component. Particularly in the case of components subjected to bending stress, the effect of particle damping can be integrated into the interior of the component without having to accept a significant loss of strength. In further work, the methodical procedure established here must be applied to the wheel carrier by integrating the effect of particle damping and testing the wheel carrier on the test bench. In particular, future work must investigate how much the damping can be increased. Furthermore, the effectiveness on fatigue strength and service life must be proven and quantified. Based on these results, economic feasibility studies of the additive repair can be carried out.

\section{ACKNOWLEDGMENTS}

This research was conducted in the scope of the research project RePARE- Regeneration of product and production systems through additive repair and refurbishment (funding reference number 033R229) which is funded by Federal Ministry of Education and Research (BMBF) within the funding measure "Resource-efficient Circular Economy - Innovative Product Cycles" (ReziProK).

\section{REFERENCES}

Andersson, O., Graichen, A., Brodin, H. and Navrotsky, V. (2017), "Developing Additive Manufacturing Technology for Burner Repair”, Journal of Engineering for Gas Turbines and Power, Vol. 139 No. 3. http://dx.doi.org/10.1115/1.4034235.

Birger, E.M., Moskvitin, G.V., Polyakov, A.N. and Arkhipov, V.E. (2011), "Industrial laser cladding: current state and future", Welding International, Vol. 25 No. 3, pp. 234-243. http://dx.doi.org/10.1080/09507116. 2010.540880

Centerline (2012), "SST Cold Spray for Rapid Prototyping of Engineering Changes. SST Case Study”, available at: https://www.supersonicspray.com/uploads/documents/Add-Sensor-Bosses-on-Engine-Block-Case-Study -SST-CS-003-PR-1_0-0312.pdf.

Ehlers, T. and Lachmayer, R. (2020), "Einsatz additiv gefertigter Partikeldämpfer - eine Übersicht", in Lachmayer, R., Rettschlag, K. and Kaierle, S. (Eds.), Konstruktion für die Additive Fertigung 2019, Springer Berlin Heidelberg, Berlin, Heidelberg, pp. 123-142. http://dx.doi.org/10.1007/978-3-662-61149-4_9.

Ehlers, T. and Lachmayer, R. (2021), "Design of a motorcycle triple clamp optimised for stiffness and damping”, in Pfingstl, S., Horoschenkoff, A., Höfer, P. and Zimmermann, M. (Eds.), Proceedings of the Munich Symposium on Lightweight Design 2020: Tagungsband zum Münchner Leichtbauseminar 2020, Springer Vieweg.

Ehlers, T., Lachmayer, R., Vajna, S. and Halle, T. (2020), "Producibility", in Vajna, S. (Ed.), Integrated Design Engineering, Springer International Publishing, Cham, pp. 287-323. http://dx.doi.org/10.1007/978-3-03019357-7_9.

Ehlers, T., Tatzko, S., Wallaschek, J. and Lachmayer, R. (2021), "Design of particle dampers for additive manufacturing”, Additive Manufacturing, Vol. 38, p. 101752. http://dx.doi.org/10.1016/j.addma.2020.101752.

Fowler, B.L., Flint, E.M. and Olson, S.E. (2000), "Effectiveness and predictability of particle damping", in Hyde, T.T. (Ed.), Smart Structures and Materials 2000: Damping and Isolation, Monday 6 March 2000, Newport Beach, CA, SPIE, pp. 356-367. http://dx.doi.org/10.1117/12.384576. 
Friend, R.D. and Kinra, V.K. (2000), "Particle Impact Damping”, Journal of Sound and Vibration, Vol. 233 No. 1, pp. 93-118. http://dx.doi.org/10.1006/jsvi.1999.2795.

Gasser, A., Backes, G., Kelbassa, I., Weisheit, A. and Wissenbach, K. (2010), "Laser Additive Manufacturing: Laser Metal Deposition (LMD) and Selective Laser Melting (SLM) in Turbo-Engine Applications", Laser Technik Journal, 2010, pp. 58-63, available at: https://onlinelibrary.wiley.com/doi/pdf/10.1002/latj. 201090029.

Jhavar, S., Paul, C.P. and Jain, N.K. (2013), "Causes of failure and repairing options for dies and molds: A review”, Engineering Failure Analysis, 2013, pp. 519-535. http://dx.doi.org/10.1016/j.engfailanal.2013. 09.006.

Künneke, T. and Zimmer, D. (2017), "Funktionsintegration additiv gefertigter Dämpfungsstrukturen bei Biegeschwingungen", in Richard, H.A., Schramm, B. and Zipsner, T. (Eds.), Additive Fertigung von Bauteilen und Strukturen, Springer Fachmedien Wiesbaden, Wiesbaden, pp. 61-74. http://dx.doi.org/10. 1007/978-3-658-17780-5_4.

Lachmayer, R. and Lippert, R.B. (2020), Entwicklungsmethodik für die Additive Fertigung, Springer Berlin Heidelberg, Berlin, Heidelberg. http://dx.doi.org/10.1007/978-3-662-59789-7.

Leino, M., Pekkarinen, J. and Soukka, R. (2016), "The Role of Laser Additive Manufacturing Methods of Metals in Repair, Refurbishment and Remanufacturing - Enabling Circular Economy”, in Physics Procedia, Vol. 83, pp. 752-760. http://dx.doi.org/10.1016/j.phpro.2016.08.077.

Lu, Z., Wang, Z., Masri, S.F. and Lu, X. (2017), "Particle impact dampers: Past, present, and future", Structural Control and Health Monitoring, Vol. 25 No. 1, e2058. http://dx.doi.org/10.1002/stc.2058.

Panossian, H.V. (1992), "Structural Damping Enhancement Via Non-Obstructive Particle Damping Technique", Journal of Vibration and Acoustics, Vol. 114 No. 1, pp. 101-105. http://dx.doi.org/10.1115/1.2930221.

Papalou, A. and Masri, S.F. (1996), "Performance of Particle Dampers Under Random Excitation", Journal of Sound and Vibration, Vol. 118 No. 4, pp. 614-621. http://dx.doi.org/10.1115/1.2888343.

Scott-Emuakpor, O., George, T., Runyon, B., Holycross, C., Langley, B., Sheridan, L., O’Hara, R., Johnson, P. and Beck, J. (2018), "Investigating Damping Performance of Laser Powder Bed Fused Components With Unique Internal Structures”, in Volume 7C: Structures and Dynamics, 11.06.2018, Oslo, Norway, ASME, V07CT35A020. http://dx.doi.org/10.1115/GT2018-75977.

Vogel, F.A., Berger, S., Özkaya, E. and Biermann, D. (2019), "Vibration Suppression in Turning TiAl6V4 Using Additively Manufactured Tool Holders with Specially Structured, Particle Filled Hollow Elements", Procedia Manufacturing, Vol. 40, pp. 32-37. http://dx.doi.org/10.1016/j.promfg.2020.02.007.

Wasono, R.S., Wahab, D. and Azman, A. (2019), “Additive Manufacturing for Repair and Restoration in Remanufacturing: An Overview from Object Design and Systems Perspectives”, Processes, Vol. 7 No. 11, p. 802. http://dx.doi.org/10.3390/pr7110802.

Wilson, J.M., Piya, C., Shin, Y.C., Zhao, F. and Ramani, K. (2014), "Remanufacturing of turbine blades by laser direct deposition with its energy and environmental impact analysis", Journal of Cleaner Production, Vol. 80, pp. 170-178. http://dx.doi.org/10.1016/j.jclepro.2014.05.084.

Wohlers, T.T. (2018), Wohlers Report: $3 d$ printing and additive manufacturing state of the industry, Wohlers Associates, Fort Collins.

Xiao, W., Li, J., Wang, S. and Fang, X. (2016), "Study on vibration suppression based on particle damping in centrifugal field of gear transmission", Journal of Sound and Vibration, Vol. 366, pp. 62-80. http://dx.doi.org/10.1016/j.jsv.2015.12.014.

Yeo, N., Pepin, H. and Yang, S.S. (2017), "Revolutionizing Technology Adoption for the Remanufacturing Industry”, in Procedia CIRP, Vol. 61, pp. 17-21. http://dx.doi.org/10.1016/j.procir.2016.11.262.

Zghair, Y.A. (2019), “Additive Repair Design Process for Aluminium Components”, Dissertation, Institut für Produktentwicklung (IPeG), Leibniz Universität Hannover, Hannover, 2019.

Zghair, Y.A. and Leuteritz, G. (2017), “Additive Repair von Multimaterialsystemen im Selektiven Laserstrahlschmelzen”, in Lachmayer R., Lippert R. (eds) Additive Manufacturing Quantifiziert. Springer Vieweg, Berlin, Heidelberg, pp. 195-215. http://dx.doi.org/10.1007/978-3-662-54113-5_13. 